\title{
A Review on Pilot-Scale Applications of Hydrothermal Treatment for Upgrading Waste Materials
}

\author{
Chinnathan Areeprasert, Dachao Ma, Patrick Prayoga, and Kunio Yoshikawa
}

\begin{abstract}
In this paper, a review on applications of hydrothermal treatment (HTT) for upgrading waste materials was presented. This work was focused on pilot-scale HTT processes that applied to several kinds of waste for alternative solid biofuel production. The HTT utilizes subcritical water condition that has special properties as an organic solvent. With the temperature around $180-240{ }^{\circ} \mathrm{C}$ and the corresponding pressure that keeps the water in the liquid phase, many reactions are induced by the subcritical water such as hydrolysis and dehydration. The waste materials that had been subjected to the HTT processes by pilot-scale reactors such as paper sludge, antibiotic residue, and municipal solid waste were reviewed herein. Moreover, a novel application of HTT on hospital waste treatment has been carried out in a pilot-scale level. Results showed positive effects and consistency with the previous research works. Thus, the HTT showed possibility to be an option for pretreating waste materials prior to final conversion processes.
\end{abstract}

Index Terms-Hydrothermal treatment, high moisture waste, pilot-scale hydrothermal, solid biofuel.

\section{INTRODUCTION}

Mixed municipal solid waste (MSW) and high water content sludge are very problematic for transportation and disposal due to either heterogeneity or high water content. These kinds of waste are tremendously difficult to manage. Firstly, water removal processes are used to improve transportability. They consist of dewatering and drying. The former is a mechanical removal of water from solid matrix by pressing, centrifuging, filtrating, etc. whereas the latter is a removal of water by evaporation such as natural drying and convective drying. Reduction of water content could also improve heating value of waste materials. Then, the dewatered waste can be burned in an incinerator. However, to remove the water inside the waste is not easy because of the bound water in lignocellulosic materials or heterogeneity characteristic of waste materials. A rotary drum dryer is widely used to treat MSW prior to the combustion; however,

Manuscript received May 25, 2015; revised August 5, 2015. This work was supported by the Department of Mechanical Engineering, Faculty of Engineering, Kasetsart University.

C. Areeprasert is with the Department of Mechanical Engineering, Faculty of Engineering, Kasetsart University, 50 Ngam Wong Wan Rd., Ladyaow Chatuchak, Bangkok 10900, Thailand (e-mail: fengcta@ku.ac.th).

D. Ma and K. Yoshikawa are with the Department of Environmental Science and Technology, Tokyo Institute of Technology, 4259 Nagatsuta-cho, Midori-ku, Yokohama, Kanagawa 226-8502, Japan (e-mail: caihechenzi@ hotmail.com, yoshikawa.k.aa@m.titech.ac.jp).

P. Prayoga was with the Department of Environmental Science and Technology, Tokyo Institute of Technology, 4259 Nagatsuta-cho, Midori-ku, Yokohama, Kanagawa 226-8502, Japan (e-mail: patrickprayogawbw@gmail.com). it consumes large amount of energy and the product quality in term of physical and chemical properties is still poor.

Therefore, an efficient and economical waste treatment technology that can improve both dewaterability and fuel properties is necessary. One of the promising methods is the hydrothermal treatment (HTT) technology. It has been used to upgrade various types of material. The HTT is similar to hydrothermal carbonization (HTC) and hydrothermal liquefaction (HTL) in term of using a subcritical water condition as a medium. Generally, the temperature and pressure condition of HTT process is tested around $160-240{ }^{\circ} \mathrm{C}$ with its corresponding pressure that keeps the water in the liquid state and the residence time is approximately 15-90 min [1]-[3]. The HTC extends the upper temperature limit to $350{ }^{\circ} \mathrm{C}$ but generally performed in-between 180 and $220{ }^{\circ} \mathrm{C}$ and it usually has significantly longer residence time (4-12 h) compared to HTT [4]-[6]. The HTL utilizes high temperature and pressure $\left(280-370{ }^{\circ} \mathrm{C}\right.$ at 10-25 MPa) with moderate residence time [7]-[9]. The objective of the HTT is to upgrade waste materials whereas the HTC and HTL aim for biochar and bio crude oil production, respectively.

Even though a comprehensive review on HTT for solid biofuel production from high moisture waste had been done by Zhao et al. [10], this paper presented updated information on the applications of HTT focusing on the pilot-scale plants that showed possibility for commercialization in the near future.

The aim of this paper was firstly to present brief discussion on the HTT process. This included general information on the properties of the subcritical water condition, important mechanism during HTT, and process parameters of HTT. Secondly, the diagram and operating procedures of the pilot-scale hydrothermal reactor were introduced. Then, the applications of HTT technology were reviewed. The practical examples reviewed herein were paper sludge, antibiotic residue, and municipal solid waste. Finally, the experiment of the pilot-scale HTT on hospital waste was reported.

\section{HydRothermal TREATMENT PROCESS}

\section{A. Subcritical Water Condition}

Water at normal condition $\left(25^{\circ} \mathrm{C}\right.$ and $\left.0.1 \mathrm{MPa}\right)$ is a good solvent for salt; however, it is incompetently miscible with hydrocarbons [11]. This is because high-density water in the liquid phase has high relative dielectric constant as shown in Table I. On the other hand, water under high temperature and pressure that is close to but still lower than a critical point $\left(374{ }^{\circ} \mathrm{C}\right.$ and $22.1 \mathrm{MPa}$ ), called subcritical water (SW), has different properties. For example, dielectric constant is 
greatly reduced as can be observed in the Table I. When it comes close to the critical point, the value of the dielectric constant approaches 10 [11] that is similar to that of dichloromethane (methylene chloride), a widely-used organic solvent. Thus, SW has high miscibility and it is able to increase a solubility of organic matters. Another important property of SW is ionic products, $\mathrm{H}_{3} \mathrm{O}^{+}$and $\mathrm{OH}^{-}$ion. The amount of these ionic products can be orders of magnitude higher than that of the normal water [7], [11]. Consequently, SW has a catalytic function. According to the special properties of high temperature and pressure SW, it is a good medium for dissolving organic compounds.

TABLE I: PROPERTIES OF WATER AT SEVERAL CONDITIONS ADAPTED FROM [7], [12]

\begin{tabular}{lccccc}
\hline \hline & $\begin{array}{c}\text { Normal } \\
\text { water }\end{array}$ & \multicolumn{3}{c}{$\begin{array}{c}\text { Subcritical water } \\
\text { condition }\end{array}$} \\
\hline Temperature $\left({ }^{\circ} \mathrm{C}\right)$ & 25 & & 250 & 300 \\
Pressure $(\mathrm{MPa})$ & 0.1 & 5 & 50 & 25 \\
Density $\left(\mathrm{g} / \mathrm{cm}^{3}\right)$ & 1 & 0.8 & 0.8 & 0.6 \\
Dielectric constant $\left(\mathrm{Fm}^{-1}\right)$ & 78.5 & 27.1 & 27.1 & 14.07 \\
Ionic product $(\mathrm{pK}$ & 14.0 & 11.2 & 11.2 & 12 \\
Dynamic viscosity $(\mathrm{mPa} \mathrm{s})$ & 0.89 & 0.11 & 0.11 & 0.064 \\
\hline \hline
\end{tabular}

\section{B. Important Mechanisms}

Essential reactions of HTT are hydrolysis, dehydration, decarboxylation, polymerization, and aromatization [11]-[13] Hydrolysis is a reaction that a compound is broken down by a water molecule. This reaction degraded main composition of biomass, i.e., polysaccharides cellulose, hemicellulose, and starch [7]. A chain hydrolysis of cellulose during HTT could yield oligomers and glucose which were further decomposed to furfural, 5-hydroxymethylfurfural, other organic acids, aldehydes, etc. and this reaction was being occur at the temperature above approximately $220{ }^{\circ} \mathrm{C}$ [14] while hemicellulose that has a relatively weaker structure was being decomposed around $160-200{ }^{\circ} \mathrm{C}$ [15]. Toor et al. summarized a conversion of carbohydrates, lignin, lipids, and protein during HTL, using SW condition that has higher temperature and pressure than the HTT [7].

Dehydration reaction during HTT plays very important role involving both chemical (loss of water molecules) and physical alternation (removal of water from the matrix of materials). The dehydration reaction reduces atomic ratio of $\mathrm{H} / \mathrm{C}$ and $\mathrm{O} / \mathrm{C}$ as carbonization process progresses. The carbonization of biomass and waste materials is generally illustrated by Van Krevelen diagram [6], [16] as shown in Fig. 1. The carbonization progressed toward left corner by reducing $\mathrm{H} / \mathrm{C}$ and $\mathrm{O} / \mathrm{C}$ atomic ratios and eventually approaching the region of low rank coal.

From Van Krevelen diagram, decarboxylation reaction play some roles during carbonization. This reaction mechanism involved the removal of the carboxyl and/or carbonyl groups [4], [16]. The degradation of carboxyl and carbonyl groups yielded $\mathrm{CO}_{2}$ (as a major gaseous product during HTT) and $\mathrm{CO}$ and this could be observed by HTT above $150{ }^{\circ} \mathrm{C}$ [17], [18]. In addition, other sources of $\mathrm{CO}_{2}$ could come from condensation reactions and the cleavage of intramolecular bonds as well as formic acid by dehydration of cellulose [12].

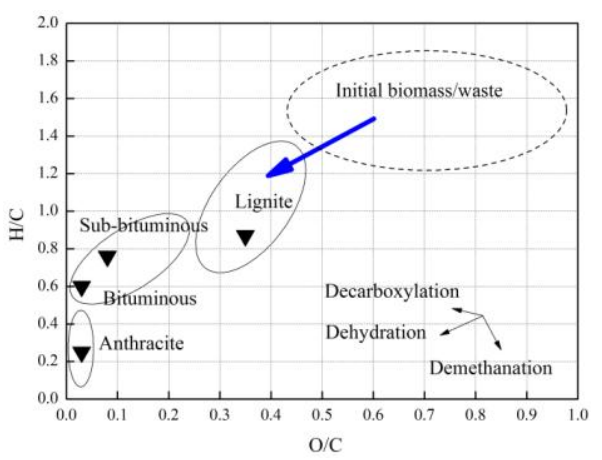

Fig. 1. Example of carbonization pathway of biomass/waste.

Other important reactions (polymerization, condensation, and aromatization) occurred as subsequent reactions after hydrolysis of cellulose [12], [14] and other soluble polymers were formed through these reactions [19]. Aromatization and aldol condensation (intermolecular dehydration) could occur simultaneously [14]. The in-depth knowledge of these reactions during the HTT are essentially missing; therefore, further investigation is necessary.

\section{Process Parameters}

Essential parameters of the HTT process are temperature, pressure, and residence time. Temperature and pressure have a mutual relation. When increasing temperature, pressure inside the reactor will increase accordingly. During the HTT, water as a solvent is retained in a liquid phase by controlling pressure. Pressure are the force that is applied to the materials, and this can influence reaction equilibrium and extractability [14]. With higher pressure, it was believed that the solvent molecules could effectively infiltrate to the matrix of the materials. Consequently, the characteristic of the products would be different from the lower one.

Hydrolysis, depolymerization, and repolymerization start after temperature rises and increases the energy to meet activation energy [20]. Depolymerization dominated at the beginning of the reaction chains whereas repolymerization played important role in the later stage [20]. The temperature condition was very important parameter and strongly affected the mechanism of the process. For example, Funke and Ziegler reported that several seconds of residence time might be adequate for a hydrolysis of glucose follow by dehydration at $270{ }^{\circ} \mathrm{C}$; however, this would take several hours at lower temperature condition, $150{ }^{\circ} \mathrm{C}$ [12]. The increase of the temperature drastically reduced time to reach the reaction.

Residence time or process holding time of SW applications has been varied from several minutes to many hours depending on the desire product. Longer holding time might increase the yield of biochar during the HTC [4], [12]. However, for the HTL, short residence time is preferred for bio-oil production. For the HTT, the variation on holding time is relatively short compared to HTC, which is generally more than an hour. The holding time of HTT is usually minimized to reduce both energy and time consumption.

\section{OPERATION OF HYDROTHERMAL TREATMENT}

The schematic of the pilot plant for hydrothermal treatment is shown in Fig. 2. Firstly, waste material is put into the reactor while the stirrer is kept rotating to facilitate the 
injection. It is important that the reactor should be preheated before adding the material since it would reduce the energy and time consumption for the treatment process. Secondly, the steam produced from boiler is injected into the reactor until the desire condition is reached. After that, the treatment process is held for a specific periods of time.

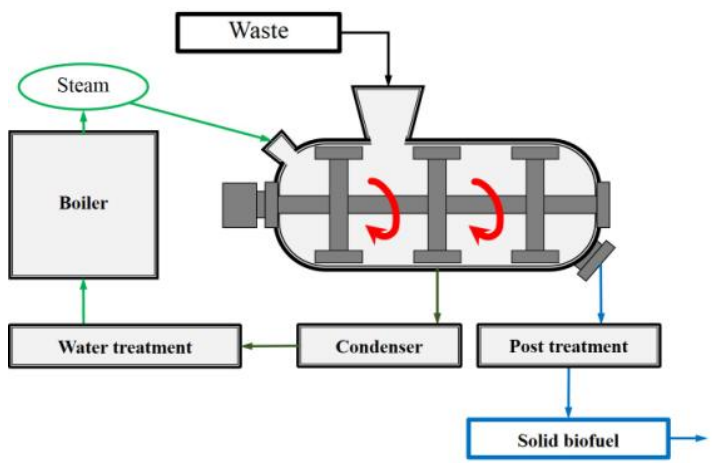

Fig. 2. Diagram of hydrothermal treatment pilot plant.

Finally, the steam in the reactor is discharged to either condenser or released to another reactor. The latter would significantly reduce the energy consumption of the process [21]. Then, the treated materials are removed from the reactor and subjected to a post treatment process such as dewatering, drying, and separation.

\section{REVIEW ON THE APPLICATIONS OF HYDROTHERMAL TREATMENT}

\section{A. Paper Sludge}

Paper sludge is a combination of pulp sludge (high fiber concentration and inorganic substances) and wastewater treatment sludge (activated sludge) from main and secondary clarifiers, respectively [22]-[24]. The sludge from wastewater treatment contains less quantity of solid particles compared to pulp sludge. Water content of paper sludge is around 76\% [1].

Areeprasert et al. performed HTT on paper sludge in both lab- and pilot-scale processes [1]. The paper sludge was subjected to HTT at the condition of $197{ }^{\circ} \mathrm{C}$ at $1.9 \mathrm{MPa}$ by a $1-\mathrm{m}^{3}$ pilot reactor. The residence time was 30 minutes. After the HTT, the treated paper sludge was dewatered by a centrifugal decanting machine and naturally dried. Finally, the produced solid biofuel was characterized in comparison with the raw material. Detail procedures and analyses of this experiment can be found in [1].

The solid fuel properties of raw paper sludge and hydrothermally treated paper sludge at the different conditions are shown in Table II. The heating value of the treated paper sludge is comparable or even better than that of the raw material. Ash of paper sludge was very high and slightly increased around $13 \%$ whereas volatile matter was reduced approximately $4 \%$ after the HTT.

The dewatering and drying performances of the treated papers sludge were significantly improved compared to the raw material [1]. Water reduction after dewatering of raw and treated paper sludge was $5.4 \%$ and $19.1 \%$, respectively. The water in the treated paper sludge can be easily removed. This was because the cell wall was crushed and bound water that needs higher temperature up to $400{ }^{\circ} \mathrm{C}$ to evaporate can be released easier [3], [25].

TABLE II: SOLID FUEL PROPERTIES OF PAPER SLUDGE ADAPTED FROM [1]

\begin{tabular}{|c|c|c|}
\hline \multirow{2}{*}{ Items } & \multicolumn{2}{|r|}{ Paper sludge } \\
\hline & Raw & $197^{\circ} \mathrm{C}, 30 \mathrm{~min}$ \\
\hline Raw material $(\mathrm{kg})$ & & $351 \pm 1$ \\
\hline Total moisture & 76.4 & $83.6^{*}$ \\
\hline $\begin{array}{l}\text { Total moisture } \\
\text { after dewatering }\end{array}$ & 72.3 & 61.8 \\
\hline \multicolumn{3}{|c|}{ Proximate analysis (\%) } \\
\hline Ash & 27.0 & 30.5 \\
\hline Volatile matter & 62.1 & 59.4 \\
\hline Fixed carbon & 10.9 & 10.1 \\
\hline \multicolumn{3}{|c|}{ Ultimate analysis (\%) } \\
\hline Carbon & 34.8 & 35.0 \\
\hline Hydrogen & 4.3 & 4.2 \\
\hline Nitrogen & 3.9 & 3.1 \\
\hline Sulfur & 0.6 & 0.6 \\
\hline Oxygen & 29.5 & 26.7 \\
\hline \multicolumn{3}{|c|}{ Heating value** $(\mathrm{MJ} / \mathrm{kg})$} \\
\hline HHV & 14.1 & 14.7 \\
\hline LHV & 11.1 & 11.6 \\
\hline
\end{tabular}

Since the water content of solid fuel plays very important role to the combustion process, the hydrothermally treated paper sludge that has lower water content would have a superior combustion performance compared to the original material. In addition, energy consumption for conventional dewatering and drying processes can be reduced. Therefore, the HTT can upgrade low quality paper sludge to solid biofuel and it would be a better option for combustion.

\section{B. Antibiotic Residue}

Antibiotic residue (AR) is a hazardous waste from medical production. It has very high water nitrogen content. The water content could be as high as $90 \%$ and very difficult to remove by simple mechanical dewatering process because it is mainly bound water [26]. Since large amount of AR is generated in China and a clean and efficient disposal is required from the government, the HTT had been utilized to upgrade the AR aiming for solid biofuel production [2].

Zhang et al. performed a pilot-scale HTT for AR [21]. The size of the pilot reactor was $2-\mathrm{m}^{3}$ and it was assembled with double stirrers. For each batch, 1.2 tons of AR was injected to the reactor and treated at the condition around $180-190{ }^{\circ} \mathrm{C}$ with the pressure of 1.1-1.3 $\mathrm{MPa}$. The holding time was around 30 minutes. After the HTT, the treated AR was dewatered by a filter pressing machine.

The results showed that the water content after dewatering process was significantly improved and the heating value was around 19.2 MJ/kg [21]. The water content after dewatering process was approximately $75 \%$ and $35 \%$ for the raw and treated AR, respectively [21].

The significant enhancement on dewatering performance was consistent with the previous presented result on paper sludge. Therefore, the HTT is a practically viable pretreatment process that could facilitate a simple mechanical dewatering to remove the water inside the sludge more efficiently. Further information on this research can be found in [21]. 


\section{Municipal Solid Waste}

Municipal solid waste (MSW) is a heterogeneous material. Its composition depends on various factors such as, geographical location, demographic, economics, culture, energy resources, and climate [27]. MSW composition generally includes biodegradable material such as food residues, leaves, scraps paper, newspapers, magazines, bags, packaging paper, plastic bottle, plastic packaging, containers, plastic bags, glass, metal, cans, textiles, leathers, ash, rubber, and other inert materials.

Prawisudha et al. applied the HTT to Japanese municipal solid waste to produce low chlorine solid biofuel [3]. The experiment was done by a $3-\mathrm{m}^{3}$ hydrothermal reactor. For the heterogeneous materials like MSW, the severity of HTT condition needs to be slightly higher than that of the homogenous waste like paper sludge or antibiotic residue. This is because MSW contains not only food residues that is easy to treat but also some materials such as plastics and rubbers, which need high temperature and longer residence time to decompose. Thus, in this experiment the HTT temperature was varied between $215{ }^{\circ} \mathrm{C}(2.0 \mathrm{MPa})$ and $235^{\circ} \mathrm{C}(2.6 \mathrm{MPa})$ with the holding time of 30 and 90 minutes [3]. It should be noted that the HTT condition including temperature and pressure could not be so high since the energy consumption for the process would be significantly increased. As a result, the process would not be feasible.

The results showed that the heating value of the hydrothermally treated Japanese MSW was comparable to low rank coals and it had a good drying performance [3]. Moreover, the solid biofuel produced from high-severity treatment condition had lower chlorine content [3]. Therefore, the HTT could convert the Japanese MSW into cleaner solid biofuel that has a comparable heating value to low rank coals. Further information including the process analysis can be found in [3].

\section{Hydrothermal TREATMENT OF Hospital WASte}

Hospital waste is a hazardous material so it is permanently sealed and prohibited to open in any cases. The hospital waste consists of a broad range of solid and liquid materials from clinic and laboratory from hospital or medical center [28]-[30]. The solid waste was suggested to be paper, food residue, textile, plastic, human body parts, diagnostic tissues, used needles and syringes, medical devices, and etc. whereas the liquid material usually were blood and liquid medicine. Among those solid wastes, the majority was belonged to plastic, food waste, paper, and textile. Small amount of incombustible solid waste, such as metal (from needles and syringes) and glass (from laboratory), were commonly disposed. Based on the composition, it can be said that the hospital waste is extremely heterogeneous. Fig. 3 shows the hospital waste sealed in plastic and cardboard boxes that used in the experiment.

Preliminary study on HTT of hospital waste was done by a $5-\mathrm{m}^{3}$ hydrothermal reactor. The pressure and temperature were varied in range of $2.0-2.4 \mathrm{MPa}$ and $207-219^{\circ} \mathrm{C}$ with the residence time of 5 minutes. Limestone was also added to enhance dechlorination effect during the HTT [31]. The experimental condition is summarized in Table III. The proximate analysis was done by TGA/DTA analyzer (Shimadzu D50). The ultimate analysis was performed by elemental analyzer and the chlorine content was determined according to the Japanese Industrialized Standard (JIS Z 7302-6:1999). The heating value analysis was done by a digital bomb calorimeter.

Table III also shows solid fuel property of hydrothermally treated hospital waste. It can be observed that the heating value is very high. This is because the original material contains plastics. However, the large plastic materials such as containers seemed to be difficult to degrade and thus, it tended to agglomerate and became a large solid particle like stone. The agglomeration problem could be alleviated by adding the biomass materials. The product appearance from the mixture of hospital waste with biomass is shown in Fig. 4.

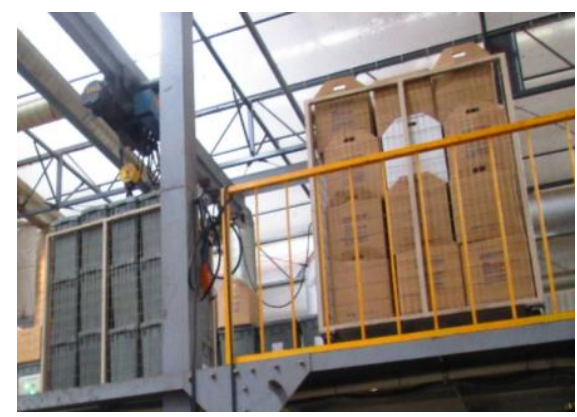

Fig. 3. Hospital waste in permanently-sealed plastic and cardboard boxes.

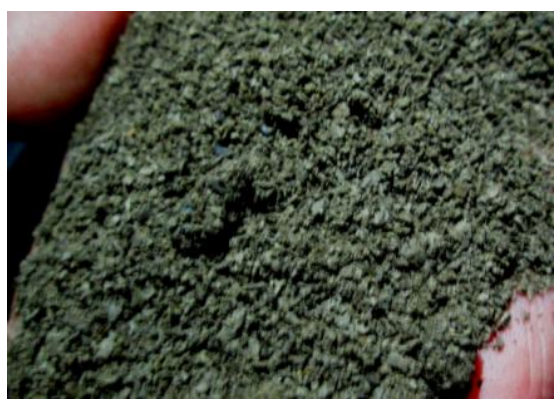

Fig. 4. Appearance of hydrothermally treated hospital waste/biomass (ratio $2: 1)$ after mechanical separation.

TABLE III: EXPERIMENTAL CONDITIONS AND SOLID FUEL PROPERTIES

\begin{tabular}{lccc}
\hline \multicolumn{1}{c}{ Conditions } & \multicolumn{3}{c}{ Batch } \\
\hline Pressure $(\mathrm{MPa})$ & 2.0 & 2.4 & 2.4 \\
Temperature $\left({ }^{\circ} \mathrm{C}\right)$ & 207 & 218 & 219 \\
Holding time $(\mathrm{min})$ & 5 & 5 & 5 \\
Limestone $(\mathrm{kg})$ & 20 & 40 & 60 \\
Raw material $(\mathrm{kg})$ & 750 & 604 & 598 \\
Proximate analysis $(\%)$ & & & \\
Ash & 8.9 & 10.3 & 13.4 \\
Volatile matter & 87.7 & 87.8 & 85.2 \\
Fixed carbon & 3.4 & 1.9 & 1.2 \\
Ultimate analysis $(\%)$ & & & \\
Carbon & 59.4 & 52.2 & 47.6 \\
Hydrogen & 8.0 & 6.2 & 7.1 \\
Nitrogen & 0.6 & 0.7 & 0.5 \\
Oxygen & 14.6 & 23.9 & 25.7 \\
HHV* $(\mathrm{MJ} / \mathrm{kg})$ & 26.4 & 25.3 & 24.3 \\
\hline *HHV: higher heating value & & \\
\hline
\end{tabular}

The PVC plastic in the hospital waste such as tube for transfusion and sample collector for urine is the source of chlorine and it poses a threat to environment by forming 
organic chlorine compounds such as dioxin during a combustion process. Therefore, the effect of the HTT conditions on the dechlorination of the hospital waste was investigated. Fig. 5 shows the distribution of chlorine both organic and inorganic. The latter is removable by water washing. It should be noted that the total chlorine content of all the samples were different because the provided original materials cannot be controlled. When increase the temperature and pressure and lower the mass input (batch 2 and 3), it can be observed that the conversion of organic chlorine into inorganic chlorine was enhanced around 10\% because the reaction was more severe. Therefore, more chlorine would be removed by a simply water washing process [31].

Based on the preliminary study on hospital waste HTT, it might be concluded that the HTT with high-severity condition could convert highly heterogeneous material into solid biofuel that contained lower amount of chlorine. Its heating value was also high. Nonetheless, the optimization on both physical characteristic and chemical property focusing on chlorine content of the product has to be further investigated.

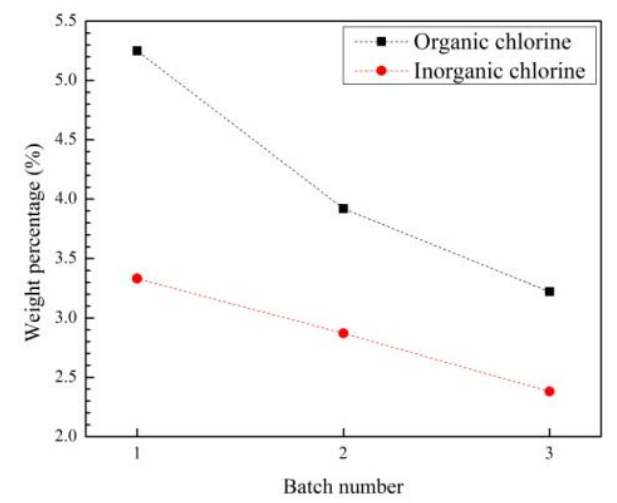

Fig. 5. Chlorine distribution of hydrothermally treated hospital waste.

\section{CONCLUSION}

This study was focused on the applications of HTT technology as an appropriate pretreatment for either heterogeneous or high moisture waste materials on the pilot-scale level. From the review work, it showed that the HTT can be implemented to sludge or similar materials that has very high moisture content. It improved dewatering and drying significantly. The solid fuel properties were comparable or even better than the original materials. Highly heterogeneous waste such as MSW and hospital waste can be treated by the HTT process as well. The product became more uniform with high-severity condition. Moreover, the chlorine content was reduced by HTT since it converted the organic chlorine to the inorganic one that is easy to remove by a washing process. In sum, the HTT showed many positive outcomes and could be an appropriate option for pretreating waste materials prior to final conversions such as combustion, gasification, anaerobic digestion, and fermentation.

\section{REFERENCES}

[1] C. Areeprasert, P. Zhao, D. Ma, Y. Shen, and K. Yoshikawa, "Alternative solid fuel production from paper sludge employing hydrothermal treatment," Energy and Fuels, vol. 28, no. 2, pp. 1198-1206, 2014.
[2] D. Ma, G. Zhang, P. Zhao, C. Areeprasert, Y. Shen, K. Yoshikawa, and G. Xu, "Hydrothermal treatment of antibiotic mycelial dreg: More understanding from fuel characteristics," Chemical Engineering Journal, vol. 273, pp. 147-155, 2015.

[3] P. Prawisudha, T. Namioka, and K. Yoshikawa, "Coal alternative fuel production from municipal solid wastes employing hydrothermal treatment," Applied Energy, vol. 90, no. 1, pp. 298-304, 2012.

[4] C. He, A. Giannis, and J. Y. Wang, "Conversion of sewage sludge to clean solid fuel using hydrothermal carbonization: Hydrochar fuel characteristics and combustion behavior," Applied Energy, vol. 111, pp. 257-266, 2013.

[5] N. D. Berge, K. S. Ro, J. Mao, J. R. Flora, M. A. Chappell, and S. Bae, "Hydrothermal carbonization of municipal waste streams," Environmental Science and Technology, vol. 45, no. 13, pp. 5696-5703, 2011

[6] I. Oliveira, D. Blohse, and H. G. Ramke, "Hydrothermal carbonization of agricultural residues," Bioresource Technology, vol. 142, pp. 138-146, 2013.

[7] S. S. Toor, L. Rosendahl, and A. Rudolf, "Hydrothermal liquefaction of biomass: A review of subcritical water technologies," Energy, vol. 36, no. 5, pp. 2328-2342, 2011.

[8] L. Zhang, P. Champagne, and C. Xu, "Bio-crude production from secondary pulp/paper-mill sludge and waste newspaper via co-liquefaction in hot-compressed water," Energy, vol. 36, no. 4, pp. 2142-2150, 2011.

[9] C. Xu and J. Lancaster, "Conversion of secondary pulp/paper sludge powder to liquid oil products for energy recovery by direct liquefaction in hot-compressed water," Water Research, vol. 42, no. 6, pp. 1571-1582, 2008

[10] P. Zhao, Y. Shen, S. Ge, Z. Chen, and K. Yoshikawa, "Clean solid biofuel production from high moisture content waste biomass employing hydrothermal treatment," Applied Energy, vol. 131, pp. 345-367, 2014.

[11] A. Kruse and E. Dinjus, "Hot compressed water as reaction medium and reactant: Properties and synthesis reactions," The Journal of Supercritical Fluids, vol. 39, no. 3, pp. 362-380, 2007.

[12] A. Funke and F. Ziegler, "Hydrothermal carbonization of biomass: A summary and discussion of chemical mechanisms for process engineering," Biofuels Bioproducts and Biorefining, vol. 4, pp. 160-177, 2010.

[13] G. Brunner, "Near critical and supercritical water. Part i. Hydrolytic and hydrothermal processes," The Journal of Supercritical Fluids, vol. 47, no. 3, pp. 373-381, 2009

[14] M. Sevilla and A. B. Fuertes, "The production of carbon materials by hydrothermal carbonization of cellulose," Carbon, vol. 47, no. 9, pp. 2281-2289, 2009.

[15] S. W. Park, C. H. Jang, K. R. Baek, and J. K. Yang, "Torrefaction and low-temperature carbonization of woody biomass: Evaluation of fuel characteristics of the products," Energy, vol. 45, no. 1, pp. 676-685, 2012.

[16] J. A. Libra, K. S. Ro, C. Kammann, A. Funke, N. D. Berge, Y. Neubauer et al., "Hydrothermal carbonization of biomass residuals: A comparative review of the chemistry, processes and applications of wet and dry pyrolysis," Biofuels, vol. 2, no. 1, pp. 71-106, 2011.

[17] J. A. Murray and D. G. Evans, "The brown-coal/water system: Part 3 Thermal dewatering of brown coal," Fuel, vol. 51, no. 4, pp. 290-296, 1972.

[18] S. Karagoz, T. Bhaskar, A. Muto, and Y. Sakata, "Comparative studies of oil compositions produced from sawdust, rice husk, lignin and cellulose by hydrothermal treatment," Fuel, vol. 84, no. 7, pp. 875-884, 2005.

[19] F. S. Asghari and H. Yoshida, "Acid-catalyzed production of 5-hydroxymethyl furfural from d-fructose in subcritical water," Industrial \& Engineering Chemistry Research, vol. 45, no. 7, pp. 2163-2173, 2006

[20] J. Akhtar and N. A. S. Amin, "A review on process conditions for optimum bio-oil yield in hydrothermal liquefaction of biomass," Renewable and Sustainable Energy Reviews, vol. 15, no. 3, pp. 1615-1624, 2011

[21] G. Y. Zhang, G. W. Xu, D. Ma, and C. X. Li, "Energy recovery from antibiotic residue via hydrothermal pretreatment coupled with air staging combustion at a pilot scale," in Proc. the 2014 International Conference on Frontier of Energy and Environment Engineering, 2014, p. 355.

[22] T. Mahmood and A. Elliott, "A review of secondary sludge reduction technologies for the pulp and paper industry," Water Research, vol. 40, no. 11, pp. 2093-2112, 2006 
[23] S. Bayr and J. Rintala, "Thermophilic anaerobic digestion of pulp and paper mill primary sludge and co-digestion of primary and secondary sludge," Water Research, vol. 46, no. 15, pp. 4713-4720, 2012.

[24] O. D. Alda and A. G. Jesús, "Feasibility of recycling pulp and paper mill sludge in the paper and board industries," Resources, Conservation and Recycling, vol. 52, no. 7, pp. 965-972, 2008.

[25] T. I. Ohm, J. S. Chae, J. E. Kim, H. K. Kim, and S. H. Moon, "A study on the dewatering of industrial waste sludge by fry-drying technology," Journal of Hazardous Materials, vol. 168, no. 1, pp. 445-450, 2009.

[26] E. Neyens, J. Baeyens, and R. Dewil, "Advanced sludge treatment affects extracellular polymeric substances to improve activated sludge dewatering," Journal of Hazardous Materials, vol. 106, no. 2, pp. 83-92, 2004

[27] H. A. Qdais, M. Hamoda, and J. Newham, "Analysis of residential solid waste at generation sites," Waste Management \& Research, vol. 15 , no. 4, pp. 395-405, 1997.

[28] M. R. Sabour, A. Mohamedifard, and H. Kamalan, "A mathematical model to predict the composition and generation of hospital wastes in Iran," Waste Management, vol. 27, no. 4, pp. 584-587, 2007.

[29] S. Altin, A. Altin, B. Elevli, and O. Cerit, "Determination of hospital waste composition and disposal methods: A case study," Polish Journal of Environmental Studies, vol. 12, no. 2, pp. 251-255, 2003.

[30] C. S. Li and F. T. Jenq, "Physical and chemical composition of hospital waste," Infection Control, vol. 14, pp. 145-150, 1993.

[31] P. Prawisudha, T. Namioka, L. Liang, and K. Yoshikawa, "Dechlorination behavior of mixed plastic waste by employing hydrothermal process and limestone additive," J. Environ. Sci. Eng, vol. 5, pp. 432-439, 2011.

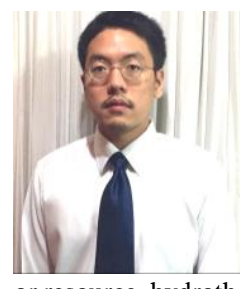

Chinnathan Areeprasert was born in Bangkok, Thailand in 1989. He obtained a bachelor of engineering in mechanical engineering, Kasetsart University in 2011. In 2013 and 2015, he received his master of engineering and doctoral of engineering from the Department of Environmental Science and Technology, Tokyo Institute of Technology, respectively. His fields of interest are waste to energy or resource, hydrothermal treatment, combustion, fluidized bed combustion, thermochemical conversion of waste and biomass, fuel conversion technology. Currently, he is working as a lecturer/researcher at Kasetsart University, Thailand.

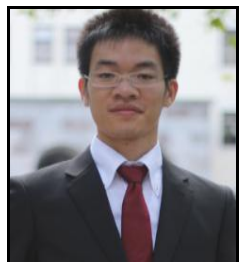

Dachao Ma was born in Nanning city, China in 1988. From 2007 to 2011 , he was trained to obtain the bachelor of engineering on thermal physics in University of Science and Technology in Beijing. In 2013 and 2015, he received his master of engineering and the doctoral of engineering from the Department of Environmental Science and Technology, Tokyo Institute of Technology, respectively. His fields of interest are chemical engineering processing for renewable energy, bio-char or biomass chemical production, combustion technologies for biomass fuel utilizations, pollutants emission fate and controlling during the combustion of biomass fuel. Currently, he is going to work as a lecturer/researcher at university in China. 